\title{
Towards rational design of low-temperature co-fired ceramic (LTCC) materials
}

\author{
Ji ZHOU* \\ State Key Laboratory of New Ceramics and Fine Processing, Tsinghua University, Beijing 100084, China
}

Received May 29, 2012; Accepted June 7, 2012

(c) The Author(s) 2012. This article is published with open access at Springerlink.com

\begin{abstract}
High performance low temperature co-fired ceramic (LTCC) dielectrics is highly desired for next generation information technology. The rational design is a key issue for the development of new LTCC materials. In comparison to the design of conventional electroceramics, more attention should be paid on the formation process of the material structure for that of LTCC, in addition to the physical properties, due to the special requirement in fabrication processing. In this paper, sintering mechanism of three types of LTCC materials, i.e., glass-ceramics, glass ceramic composite, and glass bonded ceramics, as well as important factors of their dielectric properties are discussed and summarized, and the design strategies for LTCC dielectrics, based on new matrix materials with much lower sintering temperature or higher quality, are proposed. As an example for rational design, oxyfluoride glass-ceramic based dielectrics, a new class of LTCC materials with low $\varepsilon_{\mathrm{r}}$, is analyzed.
\end{abstract}

Key words: LTCC; sintering; dielectric properties; material design

\section{Introduction}

Rapid development of information technology industry requires high integration of circuits and high density of package. With the help of semiconductor science and technology, the integration of active components doubled every 18 months, according to Moore's Law. However, for the passive components, their integration is still a challenge. As a new technology for fabrication of monolithic ceramic devices and modules with three dimensional integration structures, low temperature co-fired ceramics (LTCC) supply a possibility to for passive integration and packaging-on-system (SOP), so it has resulted in an intensive research and become one

\footnotetext{
* Corresponding author.

E-mail: zhouji@tsinghua.edu.cn
}

of the fastest growing segments in the electronics industry [1-8].

The term 'low temperature co-fired ceramic' means that the ceramic dielectric structure and conductive, resistive, and other dielectric materials are fired in same time at a relative low temperature (less than $900{ }^{\circ} \mathrm{C}$ ). This indicates that the materials will fit much more rigorous processing requirements in addition to their physical properties. The development of LTCC technology is still in the early stages. One of the bottlenecks is the ceramic dielectric materials. Over two decades, researchers paid much attention on the development and improvement of the materials, hundreds of material systems were reported [9-16]. However, only a few systems were commercialized and well-used in device products, because it is difficult to balance the processing properties, especially the low sintering temperature, and the physical properties, such 
as the low dielectric loss, of the materials, for the lack of well-established and efficient design rule for the seeking of the materials.

In this review, we try to discuss main scientific issues involved in LTCC materials and propose some strategies for material design based on the basic principles of materials science, dielectric physics, and solid state chemistry. As a successful example, we introduced the design strategy of a new lowpermittivity LTCC material system-Oxyfluoride Glass-ceramics.

\section{Physical and processing characters of LTCC materials}

The performance requirement for LTCC materials is quite similar to that for conventional elecroceramics, such as microwave ceramics and package materials [17-19]. However, the LTCC technology requires more strict processing requirements to the ceramic materials $[6,10,20-22]$, the general requirement are as follows.

(1) Low sintering temperature: It is believed that the main difficulties in the development of LTCC materials are not related to their dielectric properties but to their sintering behavior and chemical compatibility. To produce a module with ceramic dielectric materials co-fired with an inner-electrode structure and, the sintering temperature must be lower than the melting point of the electrode $[6,10]$. The typical metals for LTCCs are those with high electrical conductivity ( $\mathrm{Ag}, \mathrm{Cu}, \mathrm{Au}$ and their alloys). Among them, silver is the most usual choice because it possesses highest conductivity and chemical stability. The melting point of silver is $961{ }^{\circ} \mathrm{C}$, so the sintering temperatures of LTCC below $900{ }^{\circ} \mathrm{C}$ or lower are strictly required.

(2) Low dielectric loss: As most of LTCC devices are used in high frequency circumstance, such as wireless communication products, dielectric loss is directly involved in the power consumption and signal quality. So the low loss is the key characteristic for LTCC dielectric materials $[3,6,10,23]$. For example, the typical loss tangent for Ferro A6 is less than 0.002 at $10 \mathrm{GHz}$ [10].

(3) Low thermal expansion, good thermal resistance, and high mechanical strength: Electronic components and packages undergo heat stress during assembly processes such as in solder reflow when the components and other electronic parts are mounted on them, so it is a concern that the interconnects between the board and components will lose their connection reliability $[4,6]$. For LTCC materials, there was a need of low thermal expansion, lower thermal resistance, and high mechanical strength.

The exploration of materials satisfying both the performance and processing requirements is a big challenge for researchers. The development of the materials is an interdisciplinary topic involving many subjects (as shown in Fig.1).

\section{Material systems}

In order to ensure high sintered density of ceramics in low temperature sintering, it is common to add glasses or low melting point fluxes to the ceramic system to enhance sintering [6]. Based on microstructure, especially the state of the glass in the materials, LTCC dielectrics can be classified into three classes [24].

The first class is "Glass Ceramics (GC)". These materials are synthesized by the crystallization of glasses, so the glass content in the final materials is very high (typical $\geqslant 50 \mathrm{vol} \%$ and varies between 50 and $80 \mathrm{vol} \%$ ). The electrical properties in these materials are largely dependent on the glass phase, and the crystalline phase mainly play a role on enhancing mechanical strength and holding physical dimensions.

The second class of LTCC dielectrics belongs to "Glass Ceramic Composites (GCC)". Glass phase content in these materials is ranged from 20 to $50 \mathrm{vol} \%$. Both phases of crystal grains and glass metrics influence their physical properties, among them the glasses play the main role in the sintering process and



Fig. 1 Subjects involved in LTCC materials 
ceramic filler helps in tailoring the electric parameters, mechanical properties, and thermal properties.

The third class, so called "Glass Bonded Ceramics (GBC)", is relative new class for LTCC, but they are much similar to conventional electroceramics, the glass content is lower than other two types (about 10\% vol\%). The role of the glass serves as the low temperature sintering flux, as well as bonding agent to hold the ceramic particles. The dielectric constant of this kind of LTCC materials can be tailored in very large extent due to the large selection space of ceramic system.

The basic composition and the dielectric constant range of three classes of LTCC materials are summarized as Fig. 2. Among well-used commercial LTCC materials, Ferro A6 belongs to GC [25], whereas $\mathrm{Du}$ Pont 951 [26] belongs to GCC. Two most important material systems are Ca-B-Si-O crystallizable wollastonite by Ferro and composites of low softening point glasses (e.g., Pb-B-Si-O) and $\mathrm{Al}_{2} \mathrm{O}_{3}$ developed by DuPont. The composition and structure character of other commercial materials are listed in Table 1 [6].

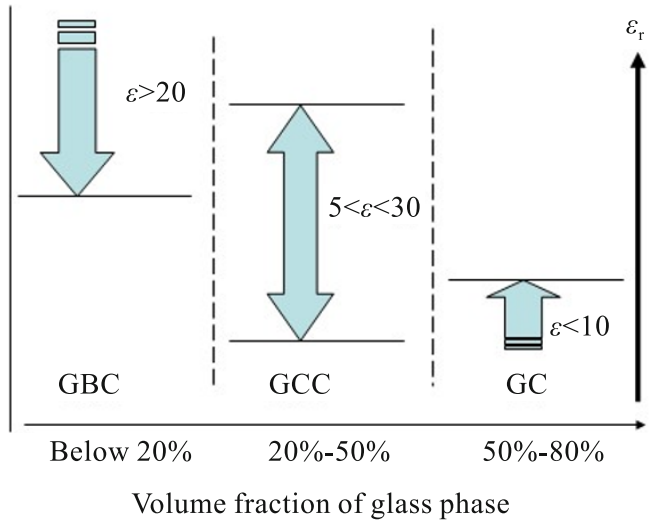

Fig. 2 Composition and dielectric constant of three classes of LTCC materials
For GC based LTCC materials, Ca-B-Si-O glass is a popular precursor due to its relative low softening point, low dielectric constant (about 6), low dielectric losses, and suitable crystallization properties [27-29].

In the GCC based LTCC systems, alumina was considered as an ideal candidate of the ceramic phase for their low permittivity, low dielectric loss and good thermomechanical performance. Many searchers investigated the effect of various glass additions on the sintering behavior and microwave dielectric properties of alumina [30-34]. Materials based on the composite of alumina and $\mathrm{Pb}-\mathrm{B}-\mathrm{Si}-\mathrm{O}, \mathrm{Ba}-\mathrm{Al}-\mathrm{Si}-\mathrm{O}$ have the dielectric constant ranged from 7 to 10 , but a little higher dielectric losses in compared with $\mathrm{Ca}-\mathrm{B}-\mathrm{Si}-\mathrm{O}-$ based glass ceramics.

A few new LTCC material systems with low permittivity are reported, such as composition of lowsoftening point glasses and $\mathrm{CaSiO}_{3}$ [35], $\mathrm{ZnAl}_{2} \mathrm{O}_{4}$ [36], $\mathrm{ZnSiO}_{4}$ [37], and Glass Ceramics of $\mathrm{CaF}_{2}-\mathrm{AlF}_{3}-\mathrm{SiO}_{2}$ [38], $\mathrm{MgO}-\mathrm{Al}_{2} \mathrm{O}_{3}-\mathrm{SiO}_{2}$ [39], $\mathrm{ZnO}-\mathrm{B}_{2} \mathrm{O}_{3}-\mathrm{SiO}_{2}$ [40], and so on.

Development of LTCC dielectrics with medium or high dielectric constant has much more space and freedom in comparison with that of low-permittivity materials. Popular strategy for the development of these materials is to take the advantage of established microwave ceramics with low sintering temperature, by add of low-softening point glassed as flux with GBC route [41-43].

\section{Sintering mechanism}

The sintering mechanism plays a key role in processing properties of LTCC materials, so a clear understanding of the mechanism is critical for the rational design of the materials. For three classes of

Table 1 Commercial LTCC materials

\begin{tabular}{|c|c|c|c|c|}
\hline LTCC supplier & Item & composition & Structure character & Dielectric constant \\
\hline Kyocera & G 55 & $\mathrm{BSG}+\mathrm{SiO} 2+\mathrm{Al}_{2} \mathrm{O}_{3}+$ cordierite & GCC & 5.0 \\
\hline Kyocera & JHB62 & $\mathrm{Pb}$-borosilicate glass $+\mathrm{Al}_{2} \mathrm{O}_{3}+\mathrm{SiO}_{2}$ & GCC & 7.9 \\
\hline Murata & BAS & $\mathrm{BaO}-\mathrm{Al}_{2} \mathrm{O}_{3}-\mathrm{SiO}_{2}$ & GCC & 6.1 \\
\hline Murata & $\mathrm{CZG}$ & $\mathrm{CaZrO}_{3}+$ glass & GBC & 25.0 \\
\hline NEC & MLS-25M & $\mathrm{Al}_{2} \mathrm{O}_{3}-\mathrm{B}_{2} \mathrm{O}_{3}-\mathrm{SiO}_{2}$ & GC & 4.7 \\
\hline NEC & MLS-41 & $\mathrm{Nd}_{2} \mathrm{O}_{3}-\mathrm{TiO}_{2}-\mathrm{SiO}_{2}$ & GBC & 19.0 \\
\hline NEC & MLS-1000 & $\mathrm{PbO}-\mathrm{Al}_{2} \mathrm{O}_{3}-\mathrm{SiO}_{2}$ & GCC & 8.0 \\
\hline NEC & GCS78 & $\mathrm{PbO}-\mathrm{BSG}$ glass $+\mathrm{Al}_{2} \mathrm{O}_{3}$ & GCC & 7.8 \\
\hline Sumitomo & LFC & $\mathrm{CaO}-\mathrm{Al}_{2} \mathrm{O}_{3}-\mathrm{SiO}_{2}-\mathrm{B}_{2} \mathrm{O}_{3}+\mathrm{Al}_{2} \mathrm{O}_{3}$ & GCC & 7.7 \\
\hline Matsushita & MKE-100 & $\mathrm{PbO}$-glass $+\mathrm{Al}_{2} \mathrm{O}_{3}$ & DCC & 7.8 \\
\hline
\end{tabular}


materials, the routes for the lowering of sintering temperature are different.

\subsection{GC mechanism}

The GC materials start with fully glassy precursors that devitrifies almost completely during the sintering process, which densifies first, followed by crystallization $[6,44]$. The formation process of their structure is as shown in Fig. 3. The physical properties of the resulting composition are controlled by the degree of crystallization, which can be enhanced by the addition of a small amount of crystalline phase acting as a nucleating agent. During the heat treatment, when the glass is transformed into a glass-ceramic material, not only complete densification should be obtained, but also sufficient crystallization must be achieved. As a result in this approach, optimization of glass-ceramic composition and further understanding of the related property differences with crystallinity is vital. A typical example for $\mathrm{CG}$ mechanism is Ferro A6M containing $\mathrm{CaO}-\mathrm{SiO}_{2}-\mathrm{B}_{2} \mathrm{O}_{3}$ glass. During firing, the crystallites of wollastonite $\left(\mathrm{CaSiO}_{3}\right)$ are formed, and some residual borosilicate glass is also present in the sintered product [28].

In most cases of GC based LTCC systems, the formation of crystals in glasses is the heterogeneous nucleation, in which the crystals are precipitated from some special areas, such as foreign elements and surfaces of particles in the glass. Some ions and clusters introduced into the base glass as the nucleation agent is representative of heterogeneous nucleation. For the glasses of silicate, aluminate, and borate, the most popular nucleation agent are $\mathrm{TiO}_{2}$ and $\mathrm{ZrO}_{2}$ $[6,10,45]$, then some transition metal oxide, such as $\mathrm{Fe}_{2} \mathrm{O}_{3}, \quad \mathrm{Cr}_{2} \mathrm{O}_{3}, \quad \mathrm{~V}_{2} \mathrm{O}_{5}$ and NiO. However, the introduction of these compounds tends to increase the dielectric loss of the ceramics.
Another factor for sintering process is relationship between nucleation temperature and nucleation speed, and the temperature for crystal growth and its speed [6]. As in Fig. 4, nucleation speed $I$ and crystal growth speed $U$ show a Gaussian distribution in relation to temperature, and at a specific temperature they reach their greatest speed. In the case of Fig. 4a, there is a big difference between the nucleation peak temperature and the crystal growth peak temperature, and as neither speed is high, the crystal nuclei formed in the glass disappear before the crystal growth temperature is reached so that verification is achieved easily. On the other hand, in the case of Fig. 4b, $I$ and $U$ are close, and at the temperature range where many nuclei are generated, crystal growth speed is high so that crystals are formed readily in the glass matrix. Suitable nucleation agent can promote two peak temperatures closer.

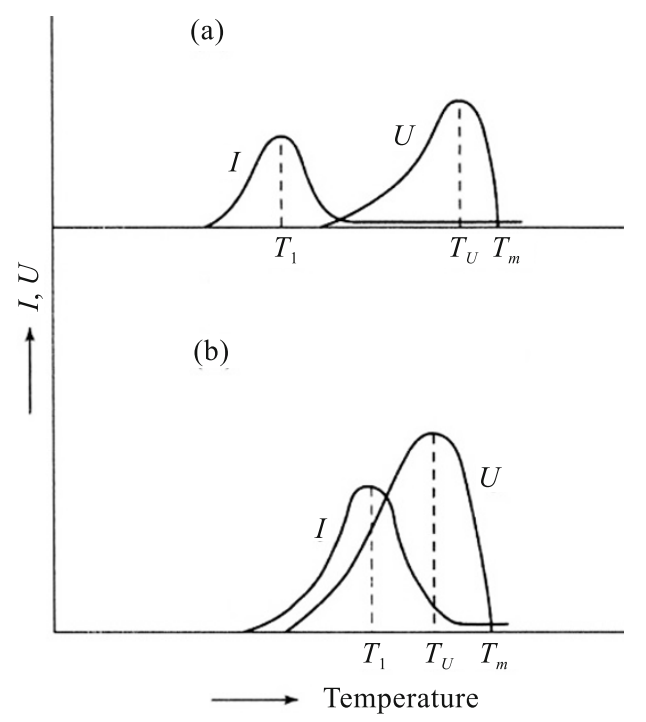

Fig. 4 The temperature dependency of nucleation speed I and crystal growth speed $U((a)$ : Vitrification occurs readily, (b) Crystals are formed readily [46]).



Fig. 3 Sintering process of GC materials 


\subsection{GCC mechanism}

For the GCC route, the starting material consists of low softening point glass and crystalline ceramic powders. The densification of glass-ceramic has been described by a three-stage liquid phase sintering by dissolution and particle rearrangement, precipitation, and solid state sintering [47], as shown in Fig. 5. The selection of glass materials is very important since the liquidation of the glass takes a dominant role in the viscous flow mechanism among the constituents $[6,10]$. The ceramic particles in the composites dissolve slightly in the glass during sintering, although the amount is small and the ceramic is characterized by lack of grain growth.

In the formation process of glass/alumina composites, alumina particles may play a role in improving crystalline process of glasses [6]. If borosilicate glass is heat treated, cristobalite crystals that have large thermal expansion are precipitated, and as well as making control of the thermal expansion of the LTCC impossible, they retard the density of the material [30]. However, when a composite is formed with alumina, precipitation of cristobalites can be suppressed, and a composite with a matrix of amorphous glass is obtained [31]. The suppression of cristobalite precipitation can be considered to be due to the alumina diffused into the glass from the alumina particles hindering the formation of crystal nuclei.
Furthermore, with glass, due to the alumina diffusing into the glass during firing, anorthites are precipitated in the glass resulting in mechanically stronger material [48].

The transition of the glass phase is key factor in the formation of GCC materials. The softening point is the temperature at which viscosity is poise, and this is used as an index of glass fluidity. A common structure for based amorphous glass is a network of Si-O modified with in which part of the network is segmented and non-bridging oxygen is formed. The constituent oxides are broadly classified into oxides that make networks, modifier oxides that break the network, and intermediate oxides that can become oxides of either type. Since modifier oxides break the network, they lower the softening point of the glass and increase its fluidity [6].

\subsection{GBC mechanism}

For the GBC materials, the sintering mechanism is quite similar with that of conventional electroceramis with liquid sintering process. In which the liquidation of the flux is the dominate mechanism, where the flux penetrates the three dimensional mesh structure formed by the ceramic particles, facilitating the wetting of each ceramic particle surface with glass melt [49], as shown in Fig.6. Therefore in order to improve the sintered density of GBC material, it is necessary to

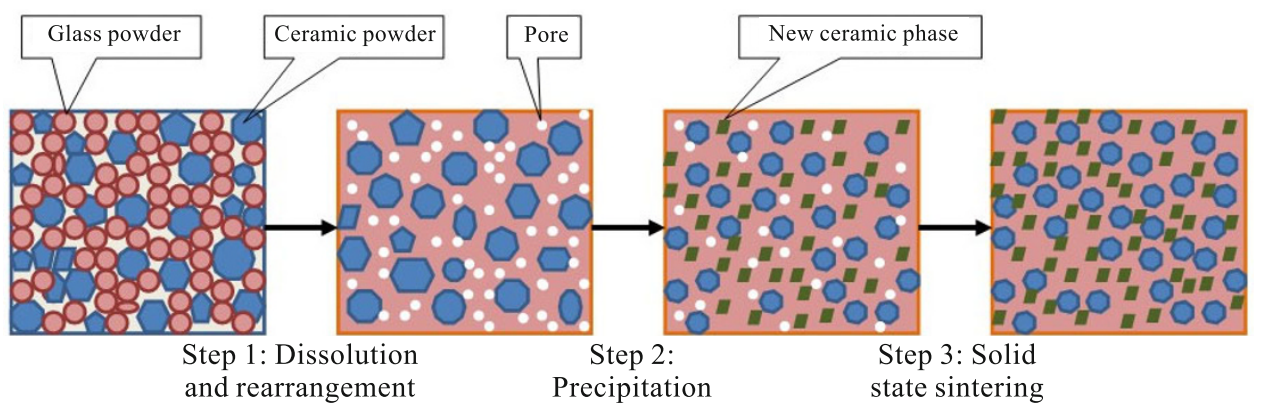

Fig.5 Sintering process of GCC materials



Fig. 6 Sintering process of GBC materials 
control the softening point of the glass material, as well as its volume and powder particle size to increase its fluidity [50]. Furthermore, since the ceramic has the effect of an impediment hindering the flow of the glass, using ceramic with a large particle size and thus a small specific surface area is beneficial from the point of view of improving the sintered density. As suggested above, factors arising from the characteristics of the glass play a very large role in low temperature firing [6].

The selection of flux is critical in the design of GBC materials. Most of fluxes are involved in the reaction in the sintering process, not only play a role in the formation of the final materials, but may enter the crystal grain to affect the electrical properties of materials. In common case, it is hopeful the amount flux is as little as possible. And ideally, the flux can be evaporated once the ceramic structure is formed in the sintering process. For dielectric ceramics, borosilicate and borate glass, such as glasses of $\mathrm{Bi}_{2} \mathrm{O}_{3}$ 、 $\mathrm{PbO}-\mathrm{B}_{2} \mathrm{O}_{3}-\mathrm{SiO}_{2} 、 \mathrm{PbO}-\mathrm{B}_{2} \mathrm{O}_{3}-\mathrm{ZnO} 、 \mathrm{ZnO}-\mathrm{B}_{2} \mathrm{O}_{2}$, and $\mathrm{BaCu}\left(\mathrm{B}_{2} \mathrm{O}_{5}\right)$ are effective fluxes [51-53], however, the introduction of $\mathrm{Pb}, \mathrm{Bi}$ and $\mathrm{B}$ will increase the dielectric loss of the materials. Generally, complex flux is more effective than single one, but the complexity of the composition may induce a decrease in material performance.

\section{Dielectric responses in LTCC materials}

LTCC dielectrics are composite structures of glass and crystals, their dielectric properties depend on the constituent materials in the composite. For a single material, the dielectric constant is derived from the contribution of electrons, ions, and microstructures with regard to polarizability and their dipole orientation. The total polarizability of the dielectric is the sum of all the polarization mechanism as follows [6].

(1) Electronic polarization: the polarization that occurs due to the shift in gravity centers of between electron cloud and atom nucleus while voltage is applied. For the ions in glass structures, the bigger the ionic radius, the more negative the charge and the larger the number of charges, the larger the polarizability of the ion.

(2) Ionic polarization: occurs when the positive ions in the crystal relatively displace the anions in an electric field.
(3) Dipole orientation: associated with the dipoles formed of the modifier ion and non-bridging oxygen in the glass, it is large in glass that includes alkali ions and $\mathrm{OH}$ - ions.

(4) Space charge polarization: polarization of migrated charges that accumulate in the vicinity of an electrode, grain boundaries within the material, and at the interfaces of dissimilar materials, without being neutralized.

In a composite, the dielectric constant is determined by the dielectric constant and volume fraction of the constituent material, and the complex form of the constituent material [54].

The dependence of dielectric loss on composition and microstructure is similar to that of dielectric constant. Four dielectric loss mechanisms exist in LTCC materials [6]:

(1) Conduction loss: come from electric conductivity;

(2) Dipole relaxation loss: from relaxation necessitated when the alkali ion, $\mathrm{OH}$ - ion and so on reciprocate between the adjacent position due to the electric field;

(3) Distortion loss: from distorts of the crystal or network structure due to the electric field, and dipole orientation occurs momentarily;

(4) Ion vibration loss: due to resonance at the proper oscillation frequency decided by the mass of structural ions and the chemical bonding strength of the surroundings.

Tailoring the dielectric constant and reducing the dielectric loss is the most rigorous part in design of LTCC materials. Normally, the dielectric constant is much easy to control in comparison to the loss, especially for the materials with medium or high permittivity, because many well-established microwave ceramics can be introduced as a ceramic phase. Minimization of dielectric loss is a challenge for the development of new LTCC materials because of the complexity of the loss mechanisms. However, some strategies can be followed according to the established principles. For example, if alkali is substituted with ions that have a large ionic radius such as barium and the like in lossy glass that includes ions with high ionic mobility such as alkali ions, loss can be reduced since the mobility of the ions can be hindered [6]. While dielectric characteristics in the microwave band are determined by ionic polarization and electronic polarization, dielectric loss through electronic polarization is small enough to be ignored, 
and the following equation can be derived from the one-dimensional lattice vibration model through ionic polarization (qualitatively extensible to threedimensional ion crystals). As the presence of lattice defects, impurities and grain boundaries are factors that increase it is effective to use raw materials with high purity to achieve low dielectric loss, and to aim for a microstructure without impurities and without the internal micro and macro flaws [55].

\section{Routes for rational design of LTCC materials}

It is shown that the material selection of LTCC dielectrics should be restricted by two factors: (1) essential property conditions: low dielectric loss, low thermal expansion, good thermal resistance, high mechanical strength, et al, and (2) processing demand: Formation at lower temperature. However, for most case, these two requirements are contradictory, and the optimum is at a critical point to balance property condition and processing demand, as shown in Fig.7. The materials composition was selected in a compulsory point, so there is no space to be improved, modified, and serialized.

To explore more space for material design, breaking above limitations is necessary. Two efforts can should be effective: (1) seeking matrix materials with lower transmission temperature on condition that the physical property requirement can be met (as Fig. 8a); and (2) increase the performance (e.g., lower the dielectric loss) of the matrix materials so that the materials can withstand composition adjustment (as Fig. $8 b$ ).

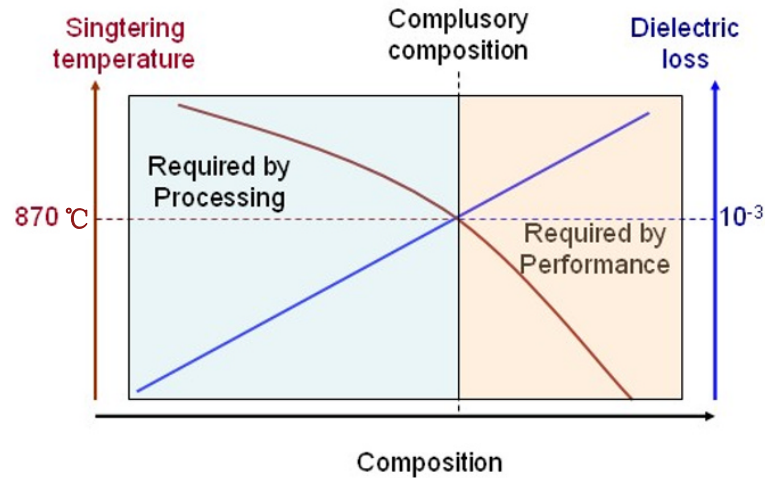

Fig.7 Composition selection of current LTCC materials

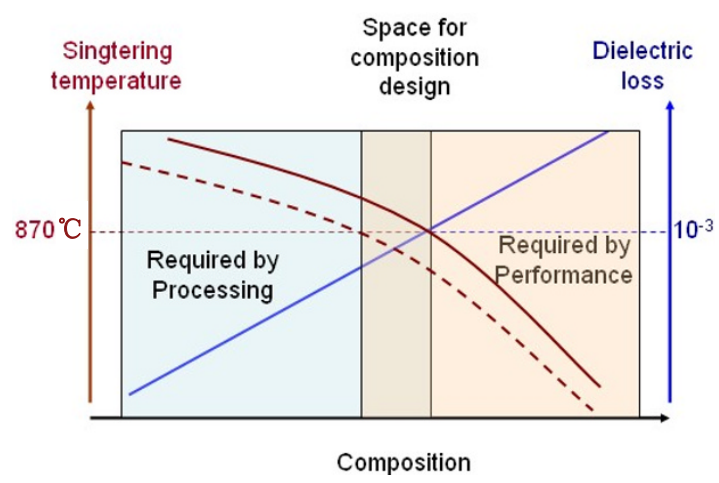

(a) lower transition temperature of matrix

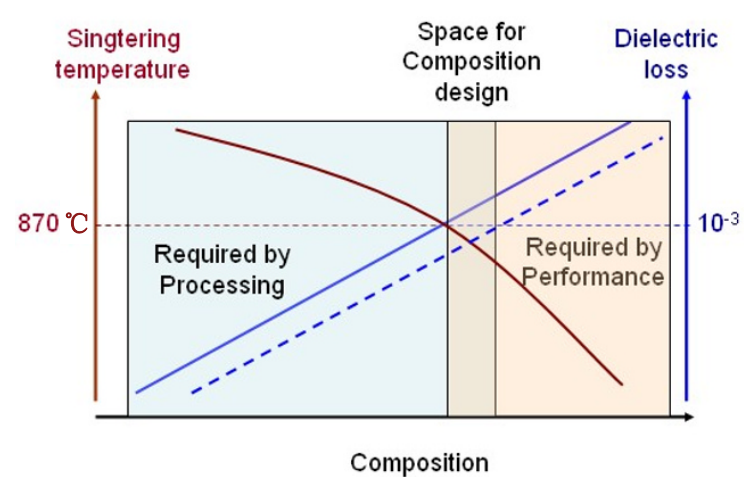

(b) increase the performance of the matrix

Fig. 8 Two route to increase the space of composition design of LTCC materials

Based on the basic principle of materials chemistry, dielectric physics, and other will-established theories, many strategies to develop new LTCC materials can be formulated. For the purpose of decrease of the reaction temperature, the selection of nucleation agents in GC based LTCC materials, the modulation of the glass network by suitable ions in GCC system, and more effective flux in GBC materials, et al, should be helpful. On other hand, composition design based on the polarization mechanism is also feasible.

\section{A successful example: oxyfluoride GC system}

LTCC dielectrics with low dielectric constant $\left(\varepsilon_{\mathrm{r}} \leqq 10\right)$ are most commonly used materials, because signal propagation is an important aspects in electronic system. In ceramic devices, the propagation delay is determined by the dielectric constant of the ceramics: $T_{\mathrm{d}} \propto \varepsilon_{\mathrm{r}}^{1 / 2}$

Although many low $\varepsilon_{\mathrm{r}}$ LTCC dielectrics were reported, the commercially available materials mainly 
belong to two systems: one is a $\mathrm{GC}$ system with the basic composition of $\mathrm{CaO}-\mathrm{B}_{2} \mathrm{O}_{3}-\mathrm{SiO}_{2}$, developed by Ferro, the other is a GCC system based on the composite of $\mathrm{Al}_{2} \mathrm{O}_{3}$ and low-melting glass developed by DuPont and Heraeus. Both of above two systems have their own disadvantages. For the former, it is hard to change the composition for modification because the increase of $\mathrm{B}_{2} \mathrm{O}_{3}$ will induce a large increase of dielectric loss and decrease of mechanical strength, and then an increase of $\mathrm{SiO}_{2}$ cause a dramatic increase of sintering temperature. For the later system, even a very small increase in the content of low-melting glasses (normally borosilicate glassed, soda-lime glasses, or lead glasses) from the composite of commercially available materials will deteriorate the loss property so that the materials can't meet the minimum basic requirement of LTCC.

One of recent research breakthroughs in low $\varepsilon_{\mathrm{r}}$ LTCC dielectrics is oxyfluoride matrixed GC system. Developed from a rational design based on the principles of solid state chemistry and dielectric physics, this materials show a excellent electrical properties and a large property tunablity, take the advantage of low transition temperature, low dielectric loss, and low dielectric constant of the matrix glass [38, 56-58]. Low- $\varepsilon_{\mathrm{r}}$ LTCC materials with serial dielectric constant from 4 to 10 was developed [59-60].

The basic strategy for the materials design is the modulation of the network of silicon-oxygen tetrahedron by the substitution of oxygen by fluorine, as shown in Fig. 9. The principles are as follows.

(1) For the aspect of physical properties, four effects of decrease in molecular polarizability of the silicon-oxygen tetrahedron network occur due to the substitution of fluorine.

(a) In the 3D network structure, the tetrahedron will be deformed from hybrid orbit of SP3 to a more flatten, lass polarizable SP2 orbital hybridization, owing to the substitution of oxygen by a atom with

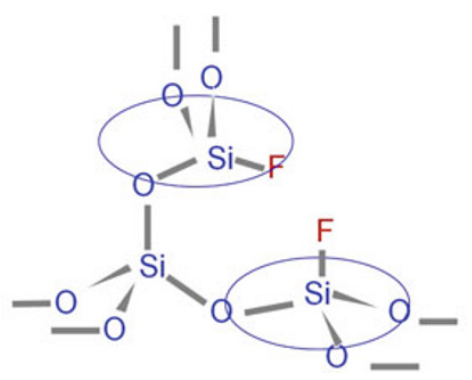

Fig. 9 Modulation in structure of silicon-oxygen tetrahedron by the substitution of oxygen by fluorine higher negativity;

(b) Si-F bond possesses a lower polarity than $\mathrm{Si}-\mathrm{O}$ bond, so the substitution cause a decrease of polarizability of the single bond;

(c) Remaining $\mathrm{SiOH}$ in silicon-oxygen tetrahedron is a main origin of polarization, and the substituted fluorine tend to replace and remove $\mathrm{OH}$, so, decrease the concentration of radicals;

(d) Because the ionicity of Si-F band is weaker than Si-O bond, the contribution of electrons in the polarization decreases with the introducing of fluorine.

(2) On the other hand, the substitution of oxygen by fluorine can increase the processing performance in two aspects:

(a) Replacement of networking Si-O bonds by non-networking Si-F bands decrease the continuity of the glass network, so induce a decrease of transition temperature of the glass;

(b) As an effective nucleation agent, fluorine promotes the nucleation process in relative low temperature.

Based on above consideration, an oxyfluoride matrixed LTCC material is designed. However, it is not easy to prepare oxyfluoride ceramics by conventional sintering process because the reaction of silicon and fluorine tend to produce volatile $\mathrm{SiF}_{4}$. Then a novel synthesis technique was developed to prepare oxyfluoride glass, in which $\mathrm{AlF}_{3}$, the precursor of fluorine, and $\mathrm{SiO}_{2}$ was melt at very high temperature to form aluminosilicate oxyfluoride glass. This final glass is the main composition for the precursor of LTCC. With the addition of some metal oxide, a series of high performance low $\varepsilon_{\mathrm{r}}$ LTCC materials were developed. The final dielectrics are the GC system with $\mathrm{Al}_{2} \mathrm{O}_{3}$ or aluminate as the crystalline phase, however, GCC system can also be explored based on oxyfluoride glass with the addition of modified ceramic phase.

With the strategy of oxyfluoride matrix material, the contradiction between high performance and low-sintering temperature in low $\varepsilon_{\mathrm{r}}$ LTCC materials was solved, a much larger space for the tailor of material properties is explored.

\section{Concluding remarks}

High performance LTCC materials are highly demanded for the development of electronics technology. Further breakthrough lies in the design of new matrix materials with much lower sintering 
temperature or higher quality. A clear understanding of the sintering and polarization mechanism is the critical for rational design of the materials, and an interdisciplinary research across solid state chemistry, dielectric physics, and the science and technology of glasses, ceramics, and crystals will be necessary for this purpose.

\section{Acknowledgement}

This work was supported by the National Natural Science Foundation of China (Grant Nos. 90922025, 51032003, and 50921061), and National High Technology Research and Development Program of China (Grant No. 2012AA030403). The author thanks Prof. Li Longtu, Prof. Bo Li, and Dr. Rui Wang, for their cooperation in related work.

\section{Reference}

[1] Baker A, Lanagan M, Randall C, et al. Integration concepts for the fabrication of LTCC structures. Int $J$ Appl Ceram Technol 2005, 2: 514-520.

[2] Wilcox DL, Huang R-F, Dai SX. Enabling materials for wireless multi-layer ceramic integrated circuit (MCIC) application. Ceram Trans 1999, 97: 201-213.

[3] Sutono A, Heo D, Chen YE, et al. High-Q LTCC-based passive library for wireless system-onpackage(SOP) module development. IEEE Trans Microw Theory Tech 2001, 49: 1715-1724.

[4] Tang C-W, You S-F. Design methodologies of LTCC bandpass filters, diplexer, and triplexer with transmission zeros. IEEE Trans Microw Theory Tech 2006, 54: 717-723.

[5] Lee C, Sutono A, Han S, et al. A compact LTCC-based Ku-band transmitter module. IEEE Trans Adv Packag 2002, 25: 374-384.

[6] Imanaka Y. Multilayered Low Temperature Cofired Ceramics (LTCC) Technology. Germany: Springer, 2005.

[7] Thelemann T, Thust H, Hintz M. Using LTCC for microsystems. Microelectron Int 2002, 19(3): 19-23.

[8] Gongora-Rubioa MR, Espinoza-Vallejosb P, Sola-Lagunac L, et al. Overview of low temperature co-fired ceramics tape technology for meso-system technology (MsST). Sens Actuator A-Phys 2001, 89(3): 222-241.

[9] Narang SB, Bahel S. Low loss dielectric ceramics for microwave applications: A review. J Ceram Process Res 2010, 11: 316-321.

[10] Sebastian MT, Jantunen H. Low loss dielectric materials for LTCC applications: A review. Int Mater Rev 2008, 53: 57-90.

[11] Dernovsek O, Eberstein M, Schiller WA. LTCC glass-ceramic composites for microwave application. J Eur Ceram Soc 2001, 21: 1693-1697.

[12] Kita J, Moos R. Development of LTCC materials and their application-an review. $J$ Microelectron Electron Compon Mater 2008, 38: 219-224.

[13] Choi Y-J, Park J-H, Ko W-J, et al. Co-firing and shrinkage matching in low- and middle-permittivity dielectric dompositions for a low-temperature co-fired ceramics system. J Am Ceram Soc 2006, 89: 562-567.

[14] Bienert C, Roosen A. Characterization and improvement of LTCC composite materials for application at elevated temperatures. J Eur Ceram Soc 2010, 30: 369-374.

[15] Gong X, Chappell WJ, Katehi LPB. Multifunctional substrates for high-frequency applications. Microw Wirel Compon Lett 2003, 13: 428-430.

[16] Eberstein M, Rabe T, Schiller WA. Influences of the glass phase on densification, microstructure, and properties of low-temperature co-fired ceramics. Int J Appl Ceram Technol 2006, 3: 428-436.

[17] Jantunen H, Kangasvieri Vähäkangas TJ, Leppävuori S. Design aspects of microwave components with LTCC technique. J Eur Ceram Soc 2003, 23: 2541-2548.

[18] Baker A, Lanagan M, Randall C, et al. Integration concepts for the fabrication of LTCC structures. Int $J$ Appl Ceram Technol 2005, 2: 514-520.

[19] Jones WK, Liu Y, Larsen B, et al. Chemical, structural, and mechanical properties of the LTCC tapes. Int J Microc Electron Packag 2000, 23(4): 469-473. 
[20] Valant M, Suvorov D. Chemical compatibility between silver electrodes and low-firing binaryoxide compounds: Conceptual study. J Am Ceram Soc 2000, 83: 2721-2729.

[21] Ollagnier JB, Guillon O, Rödel J. Viscosity of LTCC determined by discontinuous sinter-forging. Int $J$ ApplCeram Technol 2006, 3: 437-441.

[22] Lu G-Q, Sutterlin RC, Gupta TK. Effect of mismatched sintering kinetics on camber in a low-temperature cofired ceramic package. $J \mathrm{Am}$ Ceram Soc 1993, 76: 1907-1914.

[23] Mori N, Sugimoto Y, Harada J, et al. Dielectric properties of new glass-ceramics for LTCC applied to microwave or millimeter-wave frequencies. $J$ Eur Ceram Soc 2006, 26(10-11): 1925-1928.

[24] Rabe T, Gemeinert M, Schiller WA. Development of advanced low temperature cofired ceramics (LTCC). Key Eng Mater 2004, 264-268: 1181-1184.

[25] Muralidhar AS, Shaikh GJ, Roberts DL, et al. Low dielectric low temperature fried glass ceramics. US Patent 5164342, 1992.

[26] Hartmann HS. Crystallizable, low dielectric constant, low dielectric loss composition. US Patent 5024975, 1991.

[27] Chung LL, Jenq GD, Bi SC. Low temperature sintering and crystallisation behaviour of low loss anorthite-based glass-ceramics. J Mater Sci 2003, 38: 693-698.

[28] Chang CR, Jean JH. Crystallization kinetics and mechanism of low-dielectric, low-temperature, cofirable $\mathrm{CaO}-\mathrm{B}_{2} \mathrm{O}_{3}-\mathrm{SiO}_{2}$ glass-Ceramics. $J \mathrm{Am}$ Ceram Soc 1999, 82: 1725-1732.

[29] Shapiro AA, Kubota N, Yu K, et al. Stress testing of a recrystallizing $\mathrm{CaO}-\mathrm{B}_{2} \mathrm{O}_{3}-\mathrm{SiO}_{2}$ glassceramic with $\mathrm{Ag}$ electrodes for high frequency electronic packaging. J Electron Mater, 2001, 30: 386-390.

[30] Imanaka Y, Aoki S, Kamehara N, et al. Crystallization of low temperature fired glass/ceramic composite. J Ceram Soc Jpn 1987, 95: 1119-1121.

[31] Imanaka Y, Yamazaki K, Aoki S, et al. Effect of alumina addition on crystallization of borosilicate glass. J Ceram Soc Jpn 1989, 97: 309-313.

[32] Seo YJ, Jung JH, Cho YS, et al. Influences of particle size of alumina filler in an LTCC system. $J$ Am Ceram Soc 2001, 90: 649-652.

[33] Jean JH, Chang CR, Chang RL, et al. Effect of alumina particle size on prevention of crystal growth in low-k silica dielectric composite. Mater Chem Phys 1995, 40: 50-55.

[34] Müller R, Meszaros R, Peplinski B, et al. Dissolution of alumina, sintering, and crystallization in glass ceramic composites for LTCC. J Am Ceram Soc 2009, 92: 1703-1708.

[35] Wang HP, Xu SQ, Lu SQ, et al. Dielectric properties and microstructures of $\mathrm{CaSiO}_{3}$ ceramics with $\mathrm{B}_{2} \mathrm{O}_{3}$ addition. Ceram Int 2009, 35: 2715-2718.

[36] Kim KS, Shim SH, Kim S, et al. Microwave dielectric properties of ceramic/glass composites with bismuth-zinc borosilicate glass. $J$ Ceram Process Res 2010, 11: 47-51.

[37] Dou G, Zhou D, Guo M, et al. Low-temperature sintered $\mathrm{Zn}_{2} \mathrm{SiO}_{4}-\mathrm{CaTiO}_{3}$ ceramics with near-zero temperature coefficient of resonant frequency. $J$ Alloys Compd 2012, 513: 466-473.

[38] Wang R, Zhou J, Zhao H. Oxyfluoride glass-silica ceramic composite for low temperature co-fired ceramics. J Eur Ceram Soc 2008, 28(15): 2877-2881.

[39] Chen GH. Effect of replacement of $\mathrm{MgO}$ by $\mathrm{CaO}$ on sintering, crystallization and properties of $\mathrm{MgO}-\mathrm{Al}_{2} \mathrm{O}_{3}-\mathrm{SiO}_{2}$ system glass-ceramics. J Mater Sci 2007, 42: 7239-7244.

[40] Kim JR, Choi GK, Yim DK, et al. Thermal and dielectric properties of $\mathrm{ZnO}-\mathrm{B}_{2} \mathrm{O}_{3}-\mathrm{MO}_{3}$ glasses $(\mathrm{M}=\mathrm{W}, \mathrm{Mo})$. J Electroceram 2006, 17(1): 65-69.

[41] Hsiang HI, His $\mathrm{CH}$, Huang CC, et al. Sintering behavior and dielectric properties of $\mathrm{BaTiO}_{3}$ ceramics with glass addition for internal capacitor of LTCC. J Alloys Compd 2008, 459: 307-310.

[42] Kwon K, Lanagan MT, Shrout TR. Synthesis of $\mathrm{BaTiTe}_{3} \mathrm{O}_{9}$ ceramics for LTCC application and its dielectric properties. J Ceram Soc Jpn 2005, 113: 216-219.

[43] Tong JX, Zhang QL, Yang Y, et al. Low-temperature 
firing and microwave dielectric properties of $\mathrm{Ca}\left[(\mathrm{Li} 1 / 3 \mathrm{Nb} 2 / 3) 0.84 \mathrm{Ti}_{0} .16\right] \mathrm{O}_{3}-\delta$ ceramics for $\mathrm{LTCC}$ applications. J Am Ceram Soc 2007, 90: 845-849.

[44] Knickerbocker SH, Kumar AH, Herron LW. Cordierite glass-ceramics for multilayer ceramic packaging. J Am Ceram Soc Bull 1993, 72: 90-95.

[45] Lo CL, Duh JG, Chiou BS, et al. Low-temperature sintering and microwave dielectric properties of anorthite-based glass-ceramics. J Am Ceram Soc 2004, 85: 2230-2235.

[46] Frenkel J. Kinetic Theory of Liquids. UK: Oxford University Press, 1946: 424.

[47] Rao RRT. Ceramic and glass packaging in the 1990s. J Am Ceram Soc 1991, 74: 895-908.

[48] Nishigaki S, Yano S, Fukuta J, et al. A new multilayered low-temperature-fired ceramic substrate. In: Proceedings of the 1985 International Symposium of Hybrid Microelectronics (ISHM). Anaheim, USA, 1985: 225-234.

[49] Kuczynski GC, Zaplatynskyj I. Sintering of glass. $J$ Am Ceram Soc 1956, 39: 349-350.

[50] Cutler IB, Henrichsen RE. Effect of particle shape on the kinetics of sintering of glass. $J$ Am Ceram Soc 1968, 51: 604-605.

[51] Yue ZX, Yan J, Zhao F, et al. Low-temperature sintering and microwave dielectric properties of $\mathrm{ZnTiO}_{3}$-based LTCC materials. J Electroceram 2008, 21: 141-144.

[52] Shin HS, Wang JH, Kim JH. Glass infilteration in bonding of $\mathrm{BaTiO}_{2}$ and $\mathrm{Al}_{2} \mathrm{O}_{3}$ layers. Mater Sci Forum 2007, 534-536: 1457-1460.

[53] Kim MH, Lim JB, Kim JC, et al. Synthesis of $\mathrm{BaCu}\left(\mathrm{B}_{2} \mathrm{O}_{5}\right)$ ceramics and their effect on the sintering temperature and microwave dielectric properties of $\mathrm{Ba}(\mathrm{Zn} 1 / 3 \mathrm{Nb} 2 / 3) \mathrm{O}_{3}$ ceramics. $J \mathrm{Am}$ Ceram Soc 2006, 89: 3124-3128.

[54] Kingery WD, Bowen HK, Uhlmann DR. Introduction to Ceramics. John Wiley\& Sons Inc., 1976.

[55] Imanaka Y. Material technology of LTCC for high frequency application. Mater Integr 2002, 15(12): 44-48.

[56] Wang $\mathrm{R}$, Zhou J, Li B, et al. $\mathrm{CaF}_{2}-\mathrm{AlF}_{3}-\mathrm{SiO}_{2}$ glass-ceramic with low dielectric constant for LTCC application. J Alloys Compd 2010, 490: 204-207.

[57] Wang R, Zhou J, Li B, et al. Study of the properties of $\mathrm{CaF}_{2}-\mathrm{AlF}_{3}-\mathrm{SiO}_{2}$ oxyfluoride glass-ceramic system. Rare Met Mate Eng 2009, 38: 1117-1119.

[58] Wang R, Zhou J, Huang XG, et al. Oxyfluoride glassceramic composites for low temperature co-fired ceramic substrate. Ferroelectrics 2009, 388: 31-35.

[59] Zhou J, Wang R, Zhao HJ. Oxyfluoride glassceramic LTCC materials and their fabrication methods. Chinese Patent 200810056019.2.

[60] Zhou J, Wang R, Li B, et al. A glass-ceramic composite LTCC material with tunable permittivity. Chinese Patent 201010174057.5. 